Supporting Information

\title{
Composite Solid Electrolytes with NASICON-type LATP and PVdF-HFP for Solid-State
}

\author{
Lithium Batteries \\ Yang Li ${ }^{\S, a, b}$ Rachel DeWees, ${ }^{\S, a, b}$ Hui Wang*a,b
}

${ }^{a}$ Mechanical Engineering Department, University of Louisville, 332 Eastern Pkwy, Louisville, KY 40292, USA

b Conn Center for Renewable Energy Research, University of Louisville, 216 Eastern Pkwy, Louisville, KY 40208, USA

Corresponding author: hui.wang.1@louisville.edu

$\S$ These two authors contributed equally to this work. 

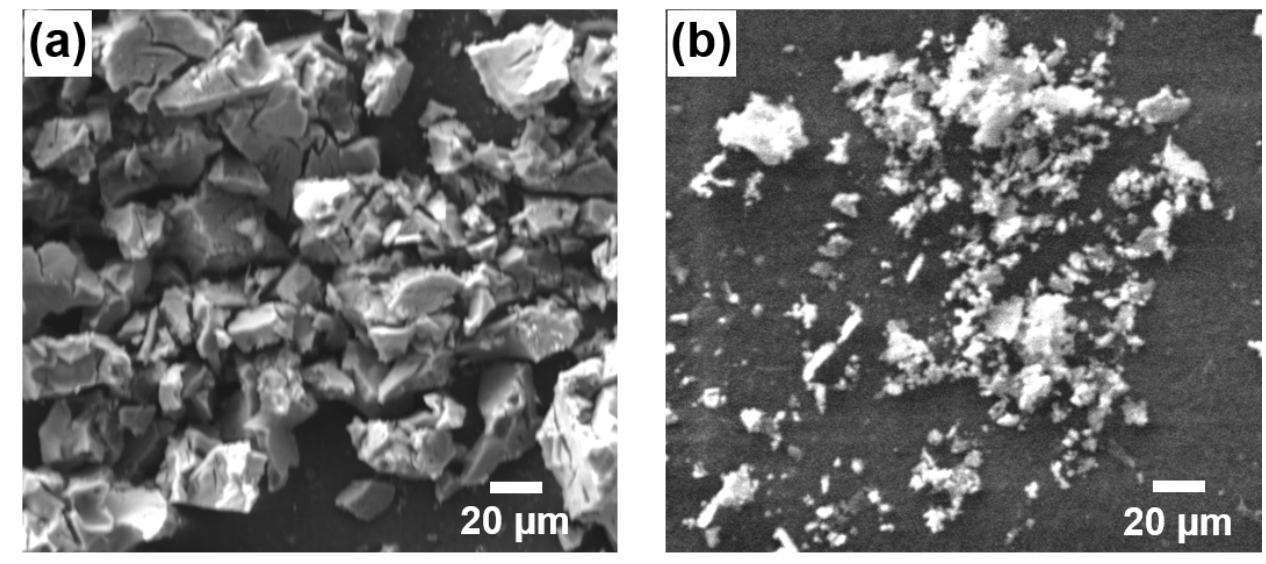

Fig.S1. SEM images of LATP particles (a) before and (b) after ball milling.

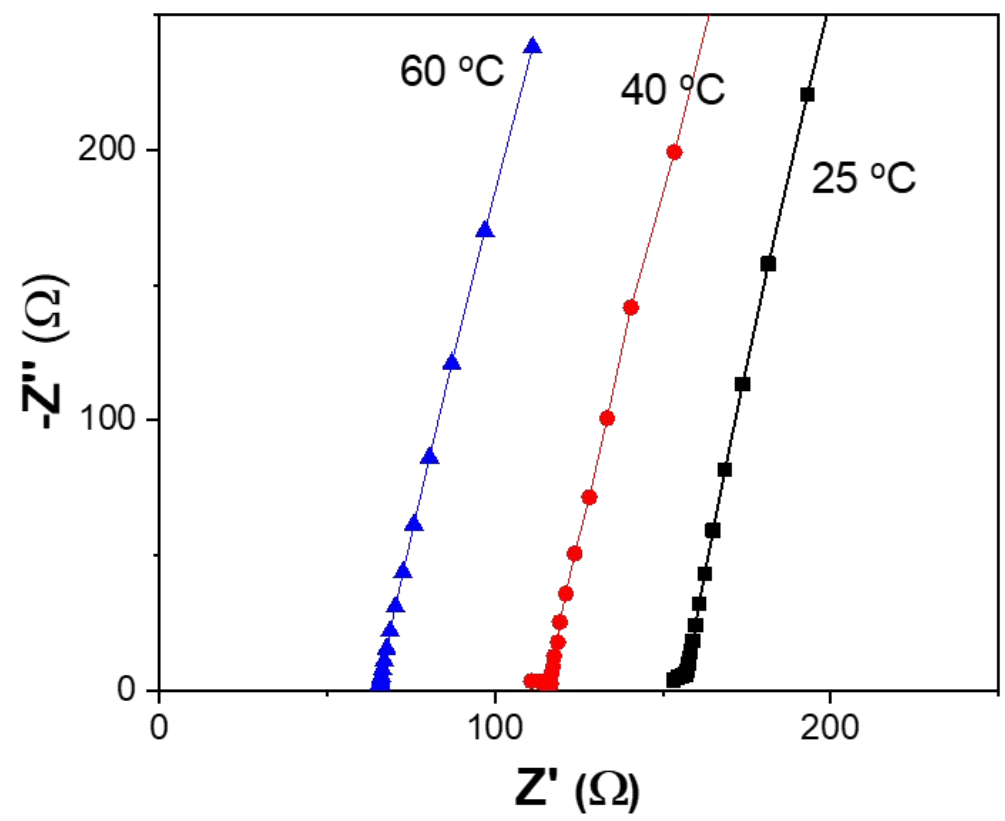

Fig.S2. Nyquist plots of CSE membrane with $10 \mathrm{wt} \%$ LATP under different temperatures (25, $\left.40,60^{\circ} \mathrm{C}\right)$. 


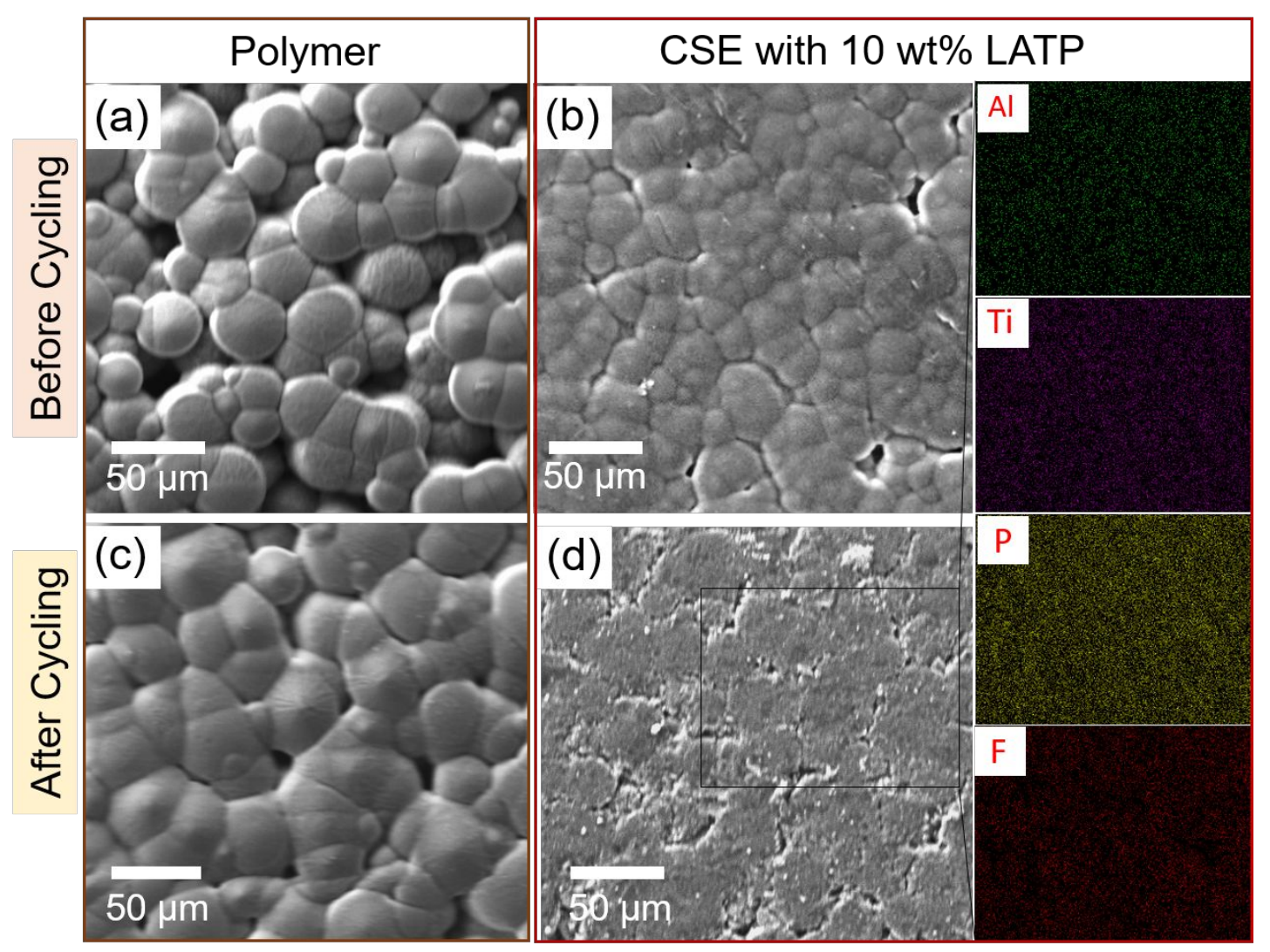

Fig.S3. SEM images of polymer electrolyte (a) before and (c) after cycling; and SEM images of CSE membrane $10 \mathrm{wt} \%$ LATP (b) before and (d) after cycling with EDS mapping (Al, Ti, P, F) in Li $\mid$ LFP cells. 

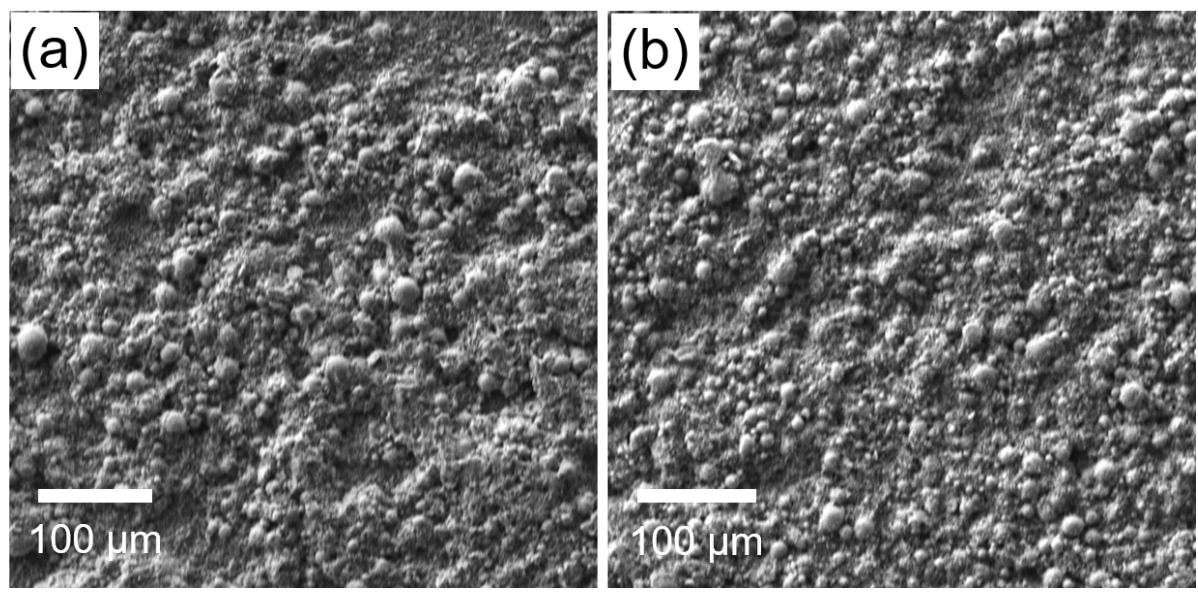

Fig.S4. SEM images of LFP cathodes from cycled Li||LFP cells using (a) polymer electrolyte and (b) CSE membrane with $10 \mathrm{wt} \%$ LATP.
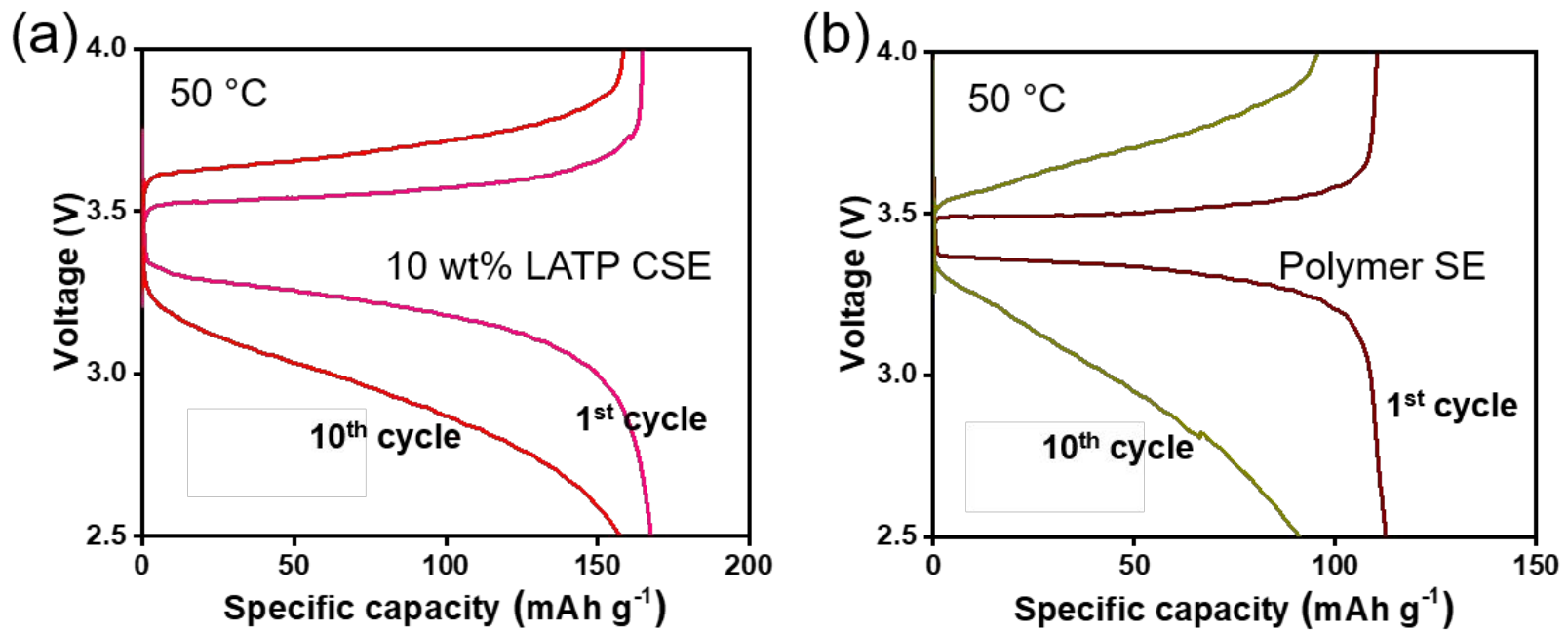

Fig.S5. At $50{ }^{\circ} \mathrm{C}$, charge-discharge curves of LFP $\|$ Li cells with (c) $10 \mathrm{wt} \%$ LATP CSE and (d) polymer electrolyte for the $1^{\text {st }}$ and $10^{\text {th }}$ cycle. 